\title{
Finite Element Modeling of Innovative Shallow Foundation System for Reactive Soils
}

\author{
Mostafa A. Ismail, Advanced Geomechanics, Perth WA, Australia \\ Mohamed A. Shahin, Curtin University, Department of Civil Engineering, Perth WA, Australia
}

\begin{abstract}
Granular pile anchor foundations (GPAF) are a promising foundation system that can be used to mitigate the serious consequences of volumetric changes of reactive soils, both during expansion and shrinkage. This paper presents results from 3D finite element analyses, using PLAXIS software, undertaken on a typical double-story building constructed over a system of GPAF in a reactive soil. The study investigates the ability of the GPAF system to resist the forces induced by soil movement due to moisture variation, and the impact of this resistance on the straining actions affecting the superstructure. The results confirm the efficiency of the GPAF system in arresting the movement of the reactive soil, which in turn improves the structural responses of the building in terms of induced deformations, angular distortions and internal forces.
\end{abstract}

\section{INTRODUCTION}

Reactive soils are clays that swell and shrink with changing moisture content, and are found in many arid and semiarid regions around the world. For example, it is estimated that $20 \%$ of the Australian surface soil can be classified as reactive [1]. There are several factors that influence the swelling and shrinking potential of clay soils, including the amount and type of clay minerals, cation exchange capacities, availability of moisture and the initial water content. The swell/shrink ground movements associated with reactive soils pose significant challenge to the geotechnical community as they cause distress to foundations of lightweight structures and cracking in retaining walls, pavements, canal beds and linings $[2,3]$.

Despite the numerous foundation systems that have been developed over the past decades to control the movements induced by reactive soils, substantial financial losses are still incurred every year in many places around the world. For example, the American Society of Civil Engineers estimated that about one quarter of all homes in the US have experienced some damage from reactive soils; the financial losses incurred by property owners exceed those caused by natural disasters such as earthquakes, floods, hurricanes and tornadoes combined [4]. In Australia, and despite the stringent regulatory requirements, most of the lightweight buildings constructed on reactive soils experience some distortional damage during their early lives [5].

The literature includes numerous solutions for construction on reactive soils, including replacement of the entire reactive material, pile foundations [6], soil stabilization using additives [7, 8], and implementation of special types of foundations such as drilled and friction piers [3]. One promising, special foundation solution that has been recently proposed is the granular pile anchor foundation (GPAF). The GPFA is an innovative technique that has shown great potential as a solution to founding structures safely into reactive soils. The GPAF system was first proposed by Phanikumar and Ramachandra Rao [9] for reactive soils under heave conditions and was later pursued by other investigators [e.g. 10, 11] via laboratory and field trials. In an attempt to determine the controlling parameters of the GPAF technique to resist the heave and shrinkage induced by reactive soils, the efficiency of the technique was further investigated numerically by Ismail and Shahin [12] using the finite element method (FEM). Despite the success of the GPAF reported by the above investigators, it is yet to be applied in practice, primarily due to the limited field trials.

In this paper, the performance of the GPAF system under heave and shrinkage is investigated by $3 \mathrm{D}$ numerical analysis for a typical double-story, four-bay structure founded in reactive soil. The investigation explored the efficiency of the system in arresting the ground movements induced by soil heave/shrinkage, and the implications of this on the internal forces experienced by the superstructure.

\section{CONCEPT OF GPAF SYSETM}

Fig. 1 shows the concept of the GPAF system, which is a hybrid solution in which a shallow foundation is supported on a granular pile that derives its resistance from the interface between the granular pile and surrounding reactive soil.

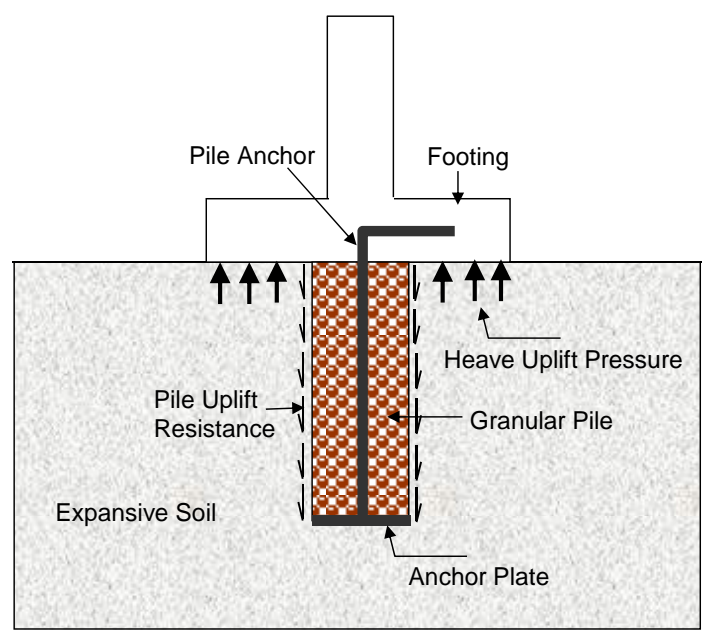

Fig. 1: Typical GPAF system 
As can be seen in Fig. 1, a typical GPAF system consists of a pile of granular material installed into the reactive soil. A concrete footing is then constructed above the granular pile and connected to it via a steel anchor that is monolithically casted with the concrete footing to transfer the load between the footing and the pile. The uplift resistance is mobilized as skin friction along the periphery of the granular pile at its interface with the surrounding soil. The force in the pile anchor is transmitted to this interface via a base plate that is rigidly connected to the pile anchor. According to this arrangement of the anchorage system between the footing and granular pile, the latter cannot only reinforce the ground (as in the case of soft clay and loose sand) but can also effectively resist the uplift forces from an expansive soil. As can be inferred from Fig. 1, the uplift resistance of the GPAF system is a function of the self-weight of the pile-footing assembly, interface shear strength, surface area of the granular pile and normal stress developed during expansion of the soil surrounding the pile. In the experiment performed by Phanikumar et al. [13], the undrained shear strength of the expansive clay surrounding the granular pile was shown to have increased by about $20 \%$, compared with the clay in the free field zone due to the expansion-induced normal stresses.

\section{NUMERICAL ANALYSES OF TWO-STORY BUILDING RESTING ON GPAF SYSTEM}

In order to investigate the efficiency of the GPAF system in practice, a two-story four-bay frame building resting on a system of GPAF is considered in the current study. The problem is analyzed by numerical modeling using the commercially available finite element software PLAXIS 3D Foundation [14].

\subsection{Problem Identification}

The two-story frame building considered in the current study is $6 \mathrm{~m}$ high (each story is $3 \mathrm{~m}$ in height), and is $20 \mathrm{~m} \times 20 \mathrm{~m}$ in plan with each bay having dimensions of $5 \mathrm{~m} \times 5 \mathrm{~m}$. A ceiling slab of $160 \mathrm{~mm}$ thick is assumed for each story. The slabs are supported by beams, $300 \mathrm{~mm}$ wide and $400 \mathrm{~mm}$ deep, which in turn rest on square columns of dimensions $300 \mathrm{~mm} \times 300$ $\mathrm{mm}$. The dead load of each structural component of the frame building is considered according to the material unit weight of that component, and an additional distributed live load of 5 $\mathrm{kPa}$ is also assumed to act on top of the slabs. All concrete materials (including footings) are made of concrete of an elastic modulus of $35 \mathrm{GPa}$, Poisson's ratio of 0.2 and unit weight of $24 \mathrm{kN} / \mathrm{m}^{3}$.

The GPAF system consists of square pad footings of dimensions $2 \mathrm{~m} \times 2 \mathrm{~m}$, each supported on a group of three granular piles of $0.5 \mathrm{~m}$ in diameter and $3.0 \mathrm{~m}$ in length. A schematic diagram of the arrangement of the three granular piles within the pad footing is shown in Fig. 2. A group of piles is used rather than a single pile to enhance the rotational stiffness and stability of the system. The problem is analyzed using the 3D model presented in Fig. 3, which has a discretized mesh that consists of 17,880 wedge elements of 15 displacement nodes and 6 Gaussian stress points each.

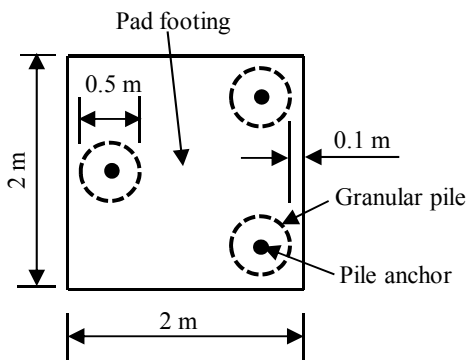

Fig. 2: Schematic diagram of the pad footing with three granular pile anchors
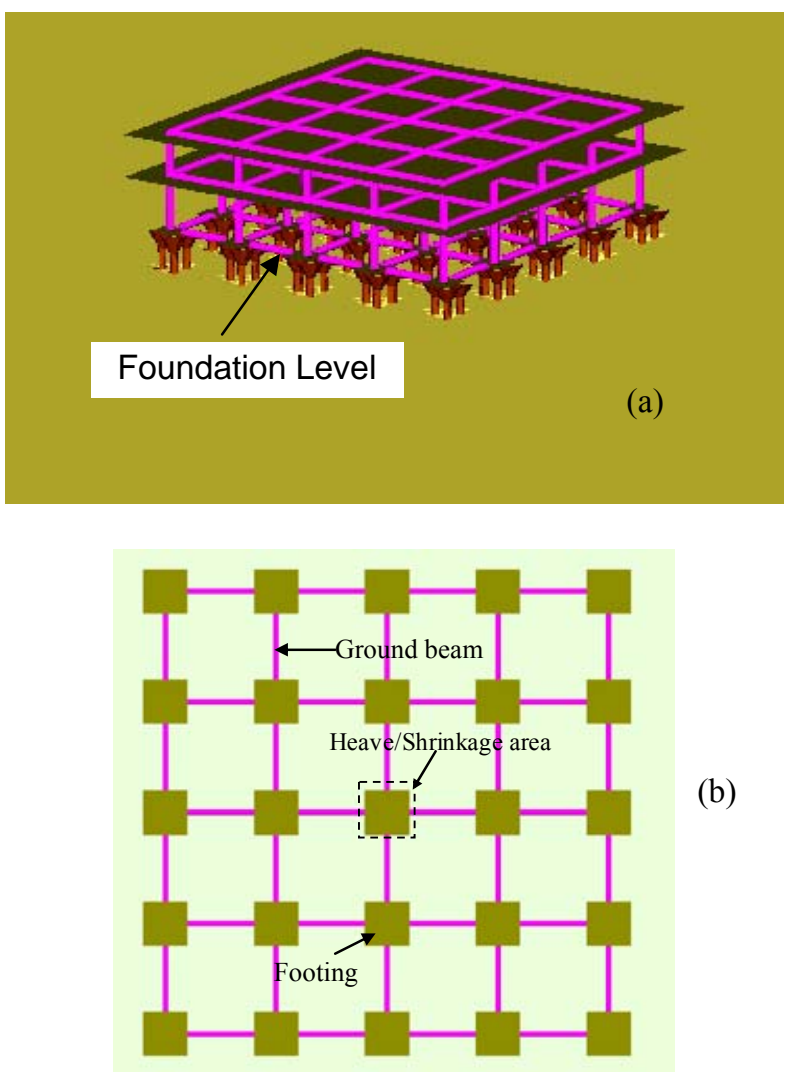

(b)

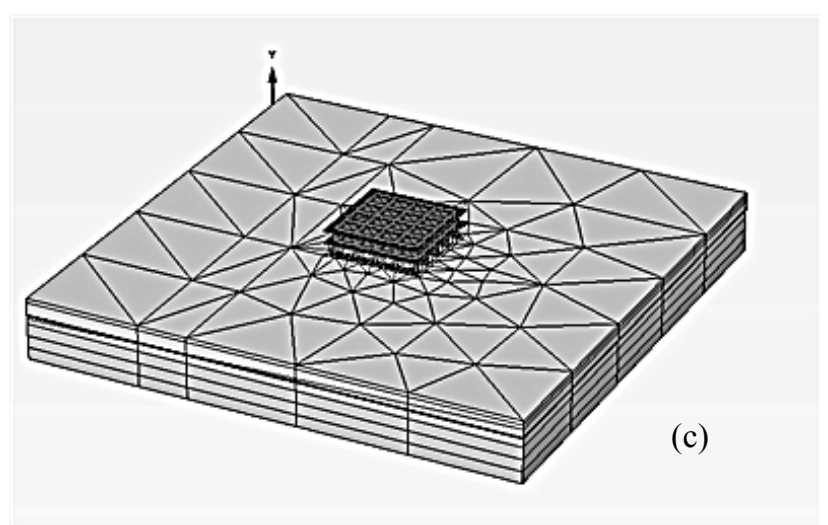

Fig. 3: FEM 3D model: (a) double-story building including GPAF system; (b) plan view of building foundation; (c) mesh discretization 
The idealized ground profile consists of a gently sloping reactive clay layer of an average thickness of $3.5 \mathrm{~m}$ (across the footing foot print) overlying dense sand of an average thickness of $11.5 \mathrm{~m}$. The model is strategically refined around the footing and granular piles to improve the accuracy of the analysis and the boundaries are located farther from the area of interest to minimize the boundary effect. The concrete footings are located $1.0 \mathrm{~m}$ below the ground surface and are modeled using a Mindlin's plate element of thickness of 0.6 $\mathrm{m}$. The pile anchor is modeled as an elastic embedded pile [14] of $75 \mathrm{~mm}$ in diameter with an elastic modulus of 200 $\mathrm{GPa}$. The steel base plate is modeled as an infinitely rigid plate. All pad footings are connected by concrete tie beams (see Fig. 3b), $300 \mathrm{~mm}$ wide and $600 \mathrm{~mm}$ deep.

\subsection{Soil Models and Parameters}

The reactive clay is modeled using a Mohr-Coulomb (MC) model and is assumed to behave in a drained manner during expansion and shrinking. The underlying dense sand and granular pile material are best modeled using the hardening soil constitutive model (HS). The HS model [15] is a non-linear elastic plastic formulation which adopts multiple yield loci as a function of plastic shear strain and a cap to allow volumetric hardening. The non-linear stress strain relationship is represented by a hyperbolic formula, with primary loading governed by a secant deformation modulus $\left(E_{50}\right)$ at $50 \%$ of the material strength. Loading and unloading within the current yield surface are assumed to be elastic (defined by a separate modulus, $E_{\mathrm{ur}}$ ) with failure governed by the Mohr-Coulomb failure criterion. Both $E_{50}$ and $E_{u r}$ evolve with the minor effective stress, $\sigma_{3}^{\prime}$, according to the following formula:

$$
E_{50}=E_{50}^{r e f}\left(\frac{c \cos \phi-\sigma_{3}^{\prime} \sin \phi}{c \cos \phi+p_{r e f} \sin \phi}\right)^{m}
$$

where: $c$ is the soil effective cohesion, $\phi$ is the effective peak friction angle, $m$ is the exponent that controls the dependency of the stiffness on stress and $p_{\text {ref }}$ is the reference stress corresponding to $E_{50}^{r e f}$. A summary of the material parameters used for all soils are presented in Table 1. It should be noted that the properties of the reactive clay are those evolving after the wetting/drying event and during expansion/shrinking. In reality, the strength of a reactive soil degrades during expansion and increases during shrinking (due to suction), but this is not modeled in this study.

The rate of volume change at which reactive clays would normally encounter depends on the location from the source of moisture and magnitude of overburden pressure. In the current study, a leaking event of an underground water facility located underneath the central column is assumed to cause arbitrary values of heave and shrinkage of $20 \%$ and $10 \%$, respectively, over the layer thickness of the affected area underneath the central footing, as shown in Fig. 3b. Both heave and shrinkage were modeled by applying equivalent volumetric strains to the affected area. The heave and shrinkage events are applied independent of each other, starting from the stage after application of the dead and live loads.

Table 1. Soil properties used in the finite element analyses

\begin{tabular}{|c|c|c|c|}
\hline \multirow{2}{*}{ Parameter } & \multicolumn{3}{|c|}{ Soil Type } \\
\cline { 2 - 4 } & $\begin{array}{c}\text { Reactive } \\
\text { Clay }\end{array}$ & $\begin{array}{c}\text { Dense } \\
\text { Sand }\end{array}$ & $\begin{array}{c}\text { Granular } \\
\text { Pile }\end{array}$ \\
\hline$\gamma\left(\mathrm{kN} / \mathrm{m}^{3}\right)^{(1)}$ & 15 & 20 & 20 \\
\hline$E_{50}^{r e f}(\mathrm{MPa})$ & 2 & 75 & 200 \\
\hline$E_{\text {oed }}^{r e f}(\mathrm{MPa})$ & - & 75 & 200 \\
\hline$E_{u r}^{r e f}(\mathrm{MPa})$ & - & 200 & 600 \\
\hline$c(\mathrm{kPa})$ & 2 & 0.1 & 0.1 \\
\hline$\phi\left({ }^{\circ}\right)$ & 24 & 36 & 40 \\
\hline$v_{u r}^{(2)}$ & 0.35 & 0.2 & 0.2 \\
\hline$p_{r e f}(\mathrm{kPa})$ & - & 100 & 100 \\
\hline$m$ & - & 0.5 & 0.5 \\
\hline$K_{0}^{(3)}$ & 0.6 & 0.4 & 0.4 \\
\hline
\end{tabular}

(1) Soil unit weight; (2) Unload-reload Poisson's ratio; (3) Coefficient of earth pressure at rest.

\section{RESULTS AND DISCUSSION}

In order to investigate the efficiency of the GPAF system in enhancing the behavior of the two-story building constructed over a reactive soil, an additional independent analysis is carried out for the building resting on pad footings without the GPAF and the results are compared with those obtained from the analysis of the building resting on the GPAF system. The comparison is made for the top beams of the central frame (i.e. beams B1 to B4 in Fig. 4). The comparison results in terms of induced deformations due to heave and shrinkage are shown in Fig. 5, and the angular distortions and bending moments due to heave are given in Table 2.

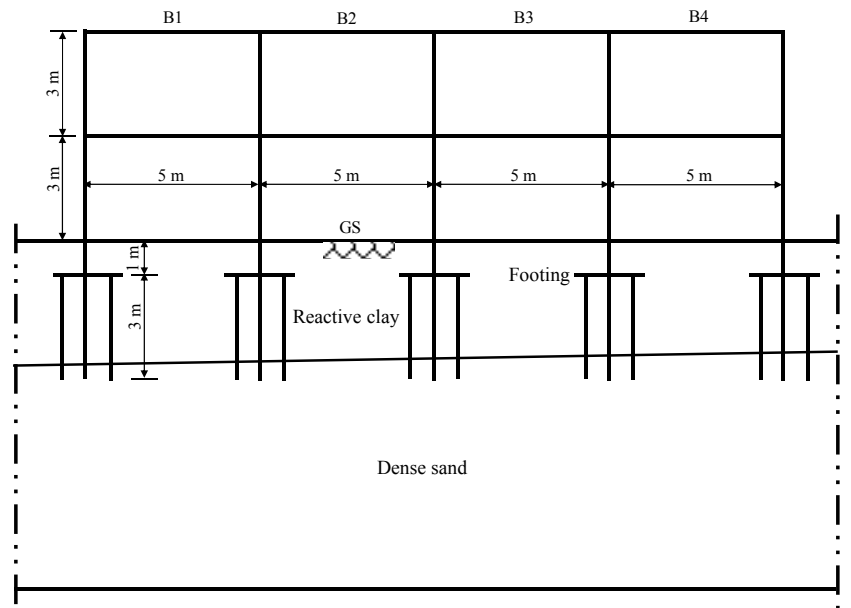

Fig. 4: Schematic diagram of the central frame

It can be seen from Fig. 5 that the ability of the pad footings to resist the vertical movements induced by soil heave is significantly improved when the GPAF system is used. The maximum vertical displacement induced by soil heave for 
beams B1-B4 without the GPAF system is found to be equal to $6.7 \mathrm{~mm}$, whereas negligible vertical movement is developed when the GPFA system is used. More importantly, it can be seen from Table 2 that all beams undergo much less angular distortions when the GPFA system is used. For example, the angular distortion of beam B2 without the GPAF system is some 300 times greater than that experienced when the GPAF system is used.

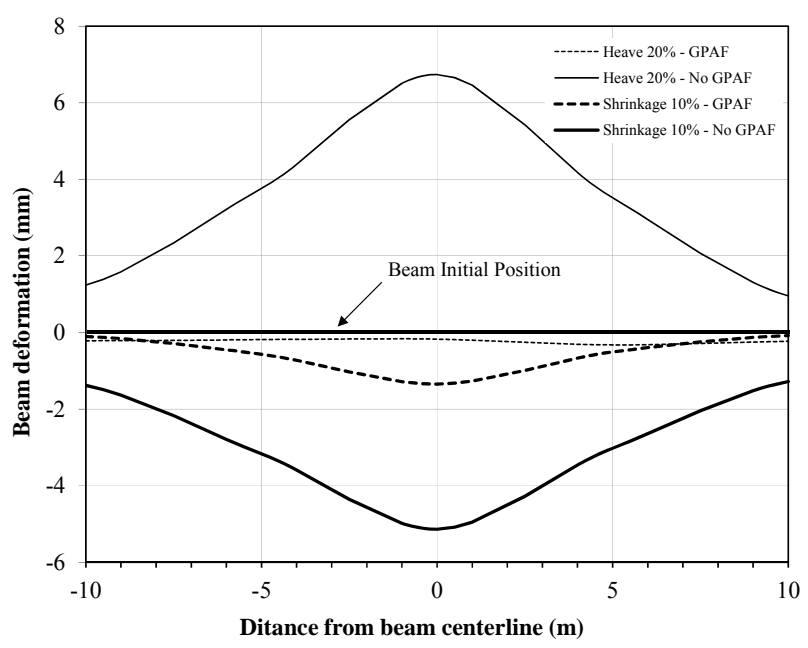

Fig. 5: Deformation of central beams B1 to B4 due to heave and shrinkage

Table 2. Angular distortions and internal forces of central beams B1 to B4 due to heave

\begin{tabular}{|c|l|c|c|c|}
\hline \multicolumn{2}{|c|}{$\begin{array}{c}\text { Beam } \\
\text { Number }\end{array}$} & $\begin{array}{c}\text { Angular } \\
\text { distortion } \\
\left(\times 10^{-5}\right)\end{array}$ & $\begin{array}{c}\text { Maximum } \\
\text { negative } \\
\text { moment } \\
(\mathrm{kN.m})\end{array}$ & $\begin{array}{c}\text { Maximum } \\
\text { positive } \\
\text { moment } \\
(\mathrm{kN} . \mathrm{m})\end{array}$ \\
\hline \multirow{2}{*}{ B1 } & GPAF & 0.6 & 44.6 & 23.0 \\
\cline { 2 - 5 } & No GPAF & 50 & 81.2 & 29.3 \\
\hline \multirow{2}{*}{ B2 } & GPAF & 0.2 & 59.8 & 26.0 \\
\cline { 2 - 5 } & No GPAF & 59 & 130.2 & 25.3 \\
\hline \multirow{2}{*}{ B3 } & GPAF & 2.8 & 58.0 & 28.0 \\
\cline { 2 - 5 } & No GPAF & 64 & 132.4 & 28.6 \\
\hline \multirow{2}{*}{ B4 } & GPAF & 1.8 & 44.0 & 25.0 \\
\cline { 2 - 5 } & No GPAF & 51 & 79.7 & 29.6 \\
\hline
\end{tabular}

Previous investigations found in the literature did not address the suitability of the GPAF system to resist shrinkage events when reactive soil loses moisture. However, it can be readily shown from Fig. 5 that under such event the GPAF system is capable of arresting the shrinkage and significantly reducing its induced settlement. It is found that the maximum beam settlement induced by soil shrinkage for the building with GPAF system is reduced by about $75 \%$ compared with the case of no GPAF system. It should be noted that the capacity of the GPAF system to resist shrinkage is a result of its ability to bear directly on the piles (while still in contact with the shrinking soil), which in turn could engage the bearing capacity of the sand layer that embrace the base plate (there are evidences that down drag forces are transferred to the shrinking soil). Given that the granular pile has no tension or bending capacity, it is therefore expected that the maximum capacity to resist shrinkage will be reached when the shrinking soil detaches itself completely from the granular pile. In such case the shrinkage resistance can be significantly improved by encasing the granular pile into a stiff, geogrid case to stop the pile from bulging.

As can be seen in Table 2, the use of the GPAF system significantly reduced the maximum negative bending moments of all beams, but slightly reduced the maximum positive bending moments. For example, the maximum negative and positive moments of beam B1 are 81.2 and 29.3 kN.m, respectively, for the case without the GPAF system, whereas these values are reduced to 44.6 and $23.0 \mathrm{kN} . \mathrm{m}$, respectively, for the case with the GPAF system.

The practical implication of the above results is that the use of the GPAF system for light-weight structures can significantly reduce the superstructure damage induced by reactive soils, leading to immense savings on the cost of structural repairs and ongoing maintenance.

\section{SUMMARY AND CONCUSIONS}

This paper presented results from 3D FEM analyses of the granular pile-anchor foundation (GPAF) system as a plausible foundation solution for light-weight structures built on reactive soils. The paper investigated the superstructure response of two-story, four-bay frame building to the ground heave/shrinkage induced by reactive soils.

The results indicate that the effect of the GPAF system in reducing the vertical displacement and angular distortion induced by soil heave are quite significant. It was shown that the maximum vertical displacement of $6.7 \mathrm{~mm}$ that is developed at the top beams of the central frame in the case of no GPAF has been totally arrested by the GPAF system, and no heave induced vertical displacement is produced. It was also shown that the GPAF system reduced the maximum angular distortion of the top beams dramatically. In accordance with this, the GPAF system is found to reduce the maximum negative and positive bending moments of the top beams by $56 \%$ and $21 \%$, respectively, compared with the maximum negative and positive bending moments produced in the case of no GPAF system. It was also observed that the resistance to shrinkage is improved immensely when the GPAF system is used. The maximum settlement induced by shrinkage for the top beams of the central frame is reduced by $75 \%$ compared with the case of no GPAF system.

The above results conclude that the GPAF system is a promising foundation technique that can be potentially used to reduce the detrimental impacts of reactive soils under both heave and shrinkage conditions. 


\section{REFERENCES}

[1] Richards BG, Peter P, and Emerson WW, "The effects of vegetation on the swelling and shrinking of soils in Australia," Geotechnique, 33(2), 1983, pp. 127-139.

[2] Al-Rawas A, and Goosen MFA, Reactive soils, recent advances in characterization and treatment. London: Taylor \& Francis, 2006.

[3] Chen FH, Foundations on reactive soils. New York: Elsevier, 1988.

[4] Wray WK, So your home is built on expansive soils: a discussion of how expansive soils affect buildings. New York: American Society of Civil Engineers, 1995.

[5] Barthur R, Jaksa MB, and Mitchell PW, "Design of residential footings built on expansive soil using probabilistic methods," in Proceedings of the 7th Australia New Zealand Conference on Geomechanics, 1996, Adelaide, pp. 369-374.

[6] Nusier OK, Alawneh AS, and Abdullatit BM, "Small-scale micropiles to control heave on reactive clays," Ground Improvement, 162(1), 2009, pp. 27-35.

[7] Ene E, and Okagbue C, "Some basic geotechnical properties of reactive soil modified using pyroclastic dust," Engineering Geology, 107(1-2), 2009, pp. 61-65.

[8] Khattab SAA, Al-Mukhtar M, and Fleureau JM, "Long-term stability characteristics of a lime-treated plastic soil," Journal of Materials in Civil Engineering, 19(4), 2007, pp. 358-366.

[9] Phanikumar BR, and Ramachandra Rao N, "Increasing pull-out capacity of granular pile anchors in reactive soils using base geosynthetics," Canadian Geotechnical Journal, 37(4), 2000, pp. 870-881.
[10] Phanikumar BR, Srirama Rao A, and Suresh K, "Field behaviour of granular pile-anchors in reactive soils," Ground Improvement, 161(G14), 2008, pp. 199-206.

[11] Sharma RS, Phanikumar BR, and Nagendra G, "Compressive load response of granular piles reinforced with geogrids," Canadian Geotechnical Journal, 41(1), 2004, pp. 187-192.

[12] Ismail AM, and Shahin MA, "Finite element analyses of granular pile anchors as a foundation option for reactive soils," in International Conference on Advances in Geotechnical Engineering, 2011, Perth, Western Australia, in press.

[13] Phanikumar BR, et al., "Granular pile anchor foundation (GPAF) system for improving the engineering behavior of expansive clay beds " Geotechnical Testing Journal, 27(3), 2004, pp. 1-9.

[14] Brinkgreve RB, and Broere W, PLAXIS 3D foundation manual, Version 2.2. The Netherland: Delft University of Technology and PLAXIS, 2008.

[15] Schanz T, Vermeer PA, and Bonnier PG, "The hardening-soil model: formulation and verification," Beyond 2000 in Computational Geotechnics, Brinkgreve RBJ, Editor. Rotterdam: Balkema, 1999, pp. 281-290.

International Journal of GEOMATE, Oct. 2011, Vol. 1, No.1 (S1. No. 1) MS No. $1 \mathrm{~h}$ received August 11, 2011, and reviewed under GEOMATE publication policies.

Copyright (C) 2011, International Journal of GEOMATE. All rights reserved, including the making of copies unless permission is obtained from the copyright proprietors. Pertinent discussion including authors' closure, if any, will be published in the Oct. 2012 if the discussion is received by April 2012.

Corresponding Author: Mohamed A. Shahin 